Original Research Paper

\title{
Prevalence of miRNAs in Introns and Cis-Regulatory Regions of Genes of the Somatotropic Axis in Mammals
}

\author{
Tatiana Shkurat, Dmitry Romanov, Evgeny Pshenichnyy, \\ Natalya Ponomareva, Anzela Alexsandrova, Georgy Bakhtadze and Svetlana Lomteva \\ Department of Genetics, Southern Federal University, Rostov-on-Don, Russia
}

\author{
Article history \\ Received: 30-10-2014 \\ Revised: 03-11-2014 \\ Accepted: 27-12-2014 \\ Corresponding Author: \\ Tatiana Shkurat \\ Department of Genetics, \\ Southern Federal University, \\ Rostov-on-Don, Russia \\ E-mail: tshkurat@yandex.ru
}

\begin{abstract}
To understand the role of microRNA in genetic control of animal growth mechanisms, we performed bioinformatic analysis of the localization of microRNAs in introns and cis-regulatory regions of the somatotropic axis genes-GH1, GHRH, SST and IGF1 in Homo sapiens, Macaca mulatta, Pan troglodytes, Pongo abelii, Gorilla gorilla, Ovis aries, Bos Taurus, Loxodonta Africana, Oryctolagus cuniculus, Canis lupus, Rattus norvegicus and Mus musculus. The results showed a significant difference in copy number of investigated microRNAs in the somatotropic axis genes surroundings in all primates. Copies of the mir-566, mir-1273, mir-1268, hsa-mir-5096 and hsamir-3929 mature sequences were frequently observed in cis-regulatory regions of these genes. The greatest number of motifs in cis-regulatory regions and introns of the investigated genes was detected for the hsa-mir5096 and hsa-mir-1268. We assume that the observed microRNAs may play an important role in the formation of morphological and physiological traits such as weight and height in mammals.
\end{abstract}

Keywords: Non-Coding DNA, Intron, Cis-Regulatory Region microRNAs, GH1 Growth Hormone, GHRH Somatoliberin SST Somatostatin, IGF1 Insulin-Like Growth Factor 1, Mammals, Primates

\section{Introduction}

In the last decade full genomes of a number of organisms have been sequenced. The genome sequencing showed that the more complex the organism is the longer and more diverse non-coding gene sequence it has. It was shown that more than $80 \%$ of non-coding DNA is involved into a variety of biochemical and regulatory processes in cells (Ecker et al., 2012). Despite these important findings we still poorly understand the mechanisms of genetic control of the mammals weight and size. Indeed, the weight of the smallest mammal Bumblebee bat is $2 \mathrm{~g}$, while the largest one, Balaenoptera musculus, weighs 150 tons. The body size of mammals may differ 75-million-fold This complicated regulation is orchestrated by the hormones of somatotropin axis (Oldham et al., 2000).

On the other hand, one of the important regulators of transcriptional and posttranscriptional gene expression is miRNAs usually accumulated in introns and intergenic spaces of the genome. miRNAs are transcribed together with the target gene and regulate its expression They are highly variable and universal. It is known that one miRNA may control up to one hundred genes. The number of combinations is increasing continuously and forms delicate hierarchical system (Bartel, 2004; Chandra et al., 2010). The feedback connection, i.e., programming by the miRNA genes, is also known. This allows us to solve a series of problems even today; for example stem cell reprogramming (Qian et al., 2010). There is an increasing interest to the study of interactions of miRNAs with the mechanisms of genetic regulation of animal growth. In the present study we performed bioinformatic analysis of the miRNA distribution in introns and gene surroundings of $G H 1$, $G H R H, S S T$ and $I G F 1$ in different mammalian species.

\section{Materials and Methods}

We analyzed localization of miRNAs in the introns and cys-regulatory regions of the genes of the Growth Hormone (GH1), Growth Hormone-Releasing factor $(G H R H)$, Somatostatin (SST) and Insulin-Like Growth Factor-1 (IGF1) in Homo sapiens, Macaca mulatta, Pan troglodytes, Pongo abelii, Gorilla gorilla, Ovis aries, Bos Taurus, Loxodonta Africana, Oryctolagus cuniculus, Canis lupus, Rattus norvegicus и Mus musculus.

Full sequences were obtained from the NCBI database (http://www.ncbi.nlm.nih.gov/) by using the set of scripts IFITCH designed for automatic data obtainment from 
NCBI. miRNA sequences were taken from the miRBase Web site (http://mirbase.org/). At the time we were doing this study miRNA database contained 28645 entries representing hairpin precursor miRNAs, expressing 35828 mature miRNA products, in 223 species.

First of all, we carried out visual analysis using the "Dotplot" program package designed in our laboratory (Shkurat et al., 2013). Visually identified multiple sequences were analyzed with "Mscanner" program designed for miRNA typing. The resulting database was filtered by using a number of SQL queries. The results of the initial GLAM2 search were filtered to yield only those matches in which there were $85 \%$ identical nucleotides for microRNA-related hairpins and for the pre-miRNA molecule.

\section{Results}

The Analysis of Correlation between the Number of Nucleotides in the Introns and the Growth Hormone Gene Surroundings and some Features of Animal Ontogenesis

We performed the analysis of correlation between the number of nucleotides in the non-coding regions of the GHI, GHRH, SST and IGFI gene surroundings and morphological and physiological traits of animals, such as adult weight, weight at birth, weight at weaning, sexual maturity, gestation, litter size, postnatal growth rate (from Gompertz function), maximum longevity residual and litters per year.

Data on the number of nucleotides in the growth hormone gene surroundings are shown in Table 1. We analyzed the genomes of animal species mentioned above, which contained the intron and intergenic spaces before and after the studied gene.

It was shown that the number of nucleotides that surrounds the somatotropin gene varied from 10 to 25 thousand base pairs in different mammals. The IGF1 gene, the product of which triggers the effects of the growth hormone, is surrounded by 140-680 thousand nucleotides.

Noncoding region and intergenic space of the $\mathrm{GH}$ gene in Gorilla gorilla had the shortest nucleotide sequence and the same gene in Bos Taurus had the longest nucleotide sequence. The number of introns in the $G H 1$ gene correlated positively with the number of litters per year in mammals $(r=0.89 \pm 0.00002)$.

Noncoding region and intergenic space of the $I G F 1$ gene in Mus musculus had the shortest nucleotide sequence (136714 b.p.) and the same gene in Loxodonta Africana had the longest nucleotide sequence ( 678338 b. p.).

The number of nucleotides in the IGFI gene surroundings correlated positively with the mass of the newborn and mature animal $\mathrm{r}=0.67 \pm 0.001$ and $\mathrm{r}=$ $0.75 \pm 0.015$ respectively) and with the age of sexual maturity onset $(\mathrm{r}=0.72 \pm 0.00007)$. The number of nucleotides in the IGF1 gene surroundings correlated negatively with the postnatal growth rate (from Gompertz function) $(\mathrm{r}=\square 0.78 \pm 0.003)$.

For other genes no correlations were found.

GLAM2-Analysis of pre-miRNA Sequences in CisRegulatory Regions of the Somatotropic Axis Genes in Mammals

Mi-RNA homologous to $85 \%$ or more to the 72 nucleotide sequences of the pre-miRNAs from the miRBase database detected in introns and non-coding DNA in cis-regulatory regions of the somatotropic axis genes are listed in Table 2.

We analyzed the localization of pre-miRNAs in noncoding DNA (30 thousand base pairs upstream to the beginning of the gene and 30 thousand pairs of nucleotides downstream from the end of the gene) in 12 mammals. We have found miRNA sequences only in primates and rodents (Table 2 and 3 ).

About 90 copies of mir-566 (homologous to miRNAs of human, chimpanzee, pongo), 79 copies of mir-1273 (homologous to miRNAs of human (a, d, e), chimpanzee, pongo), 82 copies of mir-1268 (homologous to miRNAs of human and pongo), 94 copies of hsa-mir-5096 and 16 copies of hsa-mir-3929 were localized in introns and gene surroundings of studied genes in all primates (Table 2); 10 copies of mmu-mir-3470, 1 copy of eca-mir-1244; and 1 copy mmu-mir-3471-2 were found in rodents (Table 3).

The greatest number of copies of miRNAs is localized in introns and intergenic space of the releasing hormone gene $(G H R H)$, which specifically stimulates the secretion of growth hormone (Mallo et al., 1993). This phenomenon is typical for both primates and rodents. The smallest number of miRNAs copies is identified in the SST gene surroundings.

In all studied primates we found copies of the hsamir-566 gene. Previously it was shown that motifs of the hsa-mir-566 or hsa-mir-619 hairpin homologous sequences in primates are localized in introns. The number of hairpins copies of these miRNAs was more than 280000 in the human genome and more than 290000-in chimpanzee. Moreover the percentage of hsamir-566 occurrence in the total number of all types of miRNAs located within introns of human genes was 45.34\% (Hill and Sorscher, 2013).

The data on the distribution of detected miRNAs copies in introns are presented in Table 4. Hsa-mir-566 and its homologues are not found in the introns of the GH1 gene. However, this miRNA is presented in the introns of the $I G F 1$ gene in all primates, in particular in Macaca mulatta-1 copy, Gorilla gorilla-2 copies, Pongo abelii-5 copies, Pan troglodytes-6 copies, Homo sapiens-6 copies. IGF1 gene has 4 introns in all primates except Macaca mulatta, where it has 5 introns.

pre-miRNA hsa-mir-5096 was not found in GH1 and $S S T$ introns, but it was detected from 1 to 4 copies in the introns of GHRH and IGF1 genes. 
Tatiana Shkurat et al. / American Journal of Applied Sciences 2015, 12 (1): 1-7 DOI: 10.3844/ajassp.2015.1.7

Table 1. Total number of nucleotides in the surroundings and introns of GHI, GHRH, SST and IGFI genes in different mammals

\begin{tabular}{|c|c|c|c|c|}
\hline Species & GHI & GHRH & $S S T$ & $I G F 1$ \\
\hline Homo sapiens & 17481 & 48026 & 326676 & 578609 \\
\hline Macaca mulatta & 16802 & 50054 & 331507 & 502746 \\
\hline Pan troglodytes & 17431 & 52437 & 320353 & 643936 \\
\hline Pongo abelii & 17558 & 58931 & 352525 & 284282 \\
\hline Gorilla gorilla & 10100 & 31837 & 352401 & 640319 \\
\hline Canis lupus & 17819 & 37083 & 205743 & 552701 \\
\hline Ovis aries & 23535 & 46125 & 278138 & 472880 \\
\hline Bos Taurus & 24543 & 29969 & 276901 & 247953 \\
\hline Loxodonta Africana & 17685 & 64824 & 274064 & 678338 \\
\hline Oryctolagus cuniculus & 16366 & - & 250175 & 461674 \\
\hline Mus musculus & 22605 & 41277 & 78671 & 136714 \\
\hline Rattus norvegicus & 18763 & 45895 & 149467 & 509910 \\
\hline
\end{tabular}

Table 2. Distribution of miRNAs (GLAM2) in cis-regulatory regions of the somatotropic axis genes in primates

\begin{tabular}{|c|c|c|c|c|c|c|c|c|c|c|c|c|}
\hline \multirow[b]{2}{*}{ Species } & \multicolumn{5}{|c|}{$\operatorname{mir}-566$} & \multicolumn{5}{|c|}{ mir-1273 } & \multicolumn{2}{|c|}{ mir-1268 } \\
\hline & $\begin{array}{l}\text { hsa- } \\
\text { mir- } \\
566\end{array}$ & $\begin{array}{l}\text { ppy- } \\
\text { mir- } \\
566\end{array}$ & $\begin{array}{l}\text { ptr- } \\
\text { mir- } \\
566 \\
\end{array}$ & $\begin{array}{l}\text { hsa- } \\
\text { mir- } \\
1273 a\end{array}$ & $\begin{array}{l}\text { hsa- } \\
\text { mir- } \\
1273 d\end{array}$ & $\begin{array}{l}\text { hsa- } \\
\text { mir- } \\
1273 \mathrm{e} \\
\end{array}$ & $\begin{array}{l}\text { ppy- } \\
\text { mir- } \\
1273 a\end{array}$ & $\begin{array}{l}\text { ptr- } \\
\text { mir- } \\
1273 \\
\end{array}$ & $\begin{array}{l}\text { hsa- } \\
\text { mir- } \\
1268 a\end{array}$ & $\begin{array}{l}\text { ppy- } \\
\text { mir- } \\
1268 \\
\end{array}$ & $\begin{array}{l}\text { hsa- } \\
\text { mir- } \\
3929 \\
\end{array}$ & $\begin{array}{l}\text { hsa- } \\
\text { mir- } \\
5096\end{array}$ \\
\hline \multicolumn{13}{|l|}{ GHI } \\
\hline Macaca mulatta & 0 & 0 & 0 & 0 & 0 & 0 & 0 & 0 & 0 & 2 & 0 & 4 \\
\hline Pan troglodytes & 1 & 1 & 1 & 0 & 1 & 0 & 2 & 0 & 1 & 2 & 0 & 5 \\
\hline Pongo abelii & 0 & 0 & 0 & 1 & 0 & 0 & 0 & 0 & 1 & 1 & 0 & 4 \\
\hline Homo sapiens & 2 & 1 & 0 & 0 & 1 & 0 & 1 & 0 & 0 & 2 & 1 & 6 \\
\hline $\begin{array}{l}\text { Gorilla gorilla } \\
\text { GHRH }\end{array}$ & 0 & 0 & 0 & 0 & 0 & 0 & 1 & 0 & 0 & 0 & 0 & 0 \\
\hline Macaca mulatta & 7 & 7 & 1 & 0 & 1 & 2 & 0 & 0 & 6 & 10 & 0 & 8 \\
\hline Pan troglodytes & 4 & 4 & 2 & 1 & 0 & 1 & 1 & 1 & 2 & 3 & 2 & 11 \\
\hline Pongo abelii & 3 & 4 & 3 & 1 & 0 & 1 & 1 & 1 & 2 & 5 & 2 & 11 \\
\hline Homo sapiens & 5 & 5 & 2 & 1 & 0 & 1 & 1 & 1 & 2 & 5 & 3 & 12 \\
\hline $\begin{array}{l}\text { Gorilla gorilla } \\
\text { SST }\end{array}$ & 2 & 3 & 1 & 1 & 1 & 2 & 0 & 0 & 0 & 0 & 1 & 7 \\
\hline Macaca mulatta & 0 & 0 & 0 & 1 & 0 & 0 & 2 & 1 & 1 & 1 & 0 & 1 \\
\hline Pan troglodytes & 0 & 1 & 0 & 2 & 1 & 3 & 3 & 2 & 2 & 3 & 0 & 1 \\
\hline Pongo abelii & 1 & 1 & 1 & 1 & 1 & 0 & 2 & 1 & 2 & 4 & 1 & 1 \\
\hline Homo sapiens & 0 & 1 & 0 & 3 & 1 & 2 & 3 & 2 & 3 & 5 & 1 & 0 \\
\hline $\begin{array}{l}\text { Gorilla gorilla } \\
\text { IGFI }\end{array}$ & 2 & 0 & 0 & 2 & 1 & 1 & 4 & 2 & 0 & 2 & 1 & 1 \\
\hline Macaca mulatta & 0 & 1 & 0 & 0 & 0 & 0 & 0 & 0 & 1 & 1 & 1 & 4 \\
\hline Pan troglodytes & 2 & 3 & 1 & 1 & 0 & 2 & 0 & 0 & 1 & 2 & 1 & 6 \\
\hline Pongo abelii & 2 & 2 & 1 & 0 & 1 & 3 & 0 & 0 & 0 & 3 & 1 & 2 \\
\hline Homo sapiens & 3 & 4 & 1 & 1 & 0 & 3 & 0 & 0 & 2 & 3 & 1 & 5 \\
\hline Gorilla gorilla & 2 & 2 & 0 & 0 & 0 & 2 & 0 & 0 & 1 & 2 & 1 & 5 \\
\hline
\end{tabular}

Table 3. Distribution of microRNAs (GLAM2) in cis-regulatory regions of the somatotropic axis genes in rodents

\begin{tabular}{|c|c|c|c|c|}
\hline \multirow[b]{2}{*}{ Species } & \multirow[b]{2}{*}{ mmu-mir-3471-2 } & \multirow[b]{2}{*}{ eca-mir-1244 } & \multicolumn{2}{|l|}{ mmu-mir-3470 } \\
\hline & & & mmu-mir-3470a & mmu-mir-3470b \\
\hline \multicolumn{5}{|l|}{ GHI } \\
\hline Mus musculus & 0 & 0 & 1 & 4 \\
\hline Rattus norvegicus & 0 & 0 & 1 & 0 \\
\hline \multicolumn{5}{|l|}{ GHRH } \\
\hline Mus musculus & 0 & 0 & 0 & 3 \\
\hline Rattus norvegicus & 0 & 1 & 0 & 0 \\
\hline \multicolumn{5}{|l|}{ SST } \\
\hline Mus musculus & 1 & 0 & 0 & 1 \\
\hline Rattus norvegicus & 0 & 0 & 0 & 0 \\
\hline \multicolumn{5}{|l|}{$I G F 1$} \\
\hline Mus musculus & 0 & 0 & 0 & 0 \\
\hline Rattus norvegicus & 0 & 0 & 0 & 0 \\
\hline
\end{tabular}


Table 4. Distribution of miRNAs in introns of the somatotropic axis genes

\begin{tabular}{|c|c|c|c|c|c|c|c|c|c|c|c|c|}
\hline \multirow[b]{2}{*}{ Species } & \multicolumn{5}{|c|}{$\operatorname{mir}-566$} & \multicolumn{5}{|c|}{$\operatorname{mir}-1273$} & \multicolumn{2}{|c|}{$\operatorname{mir}-1268$} \\
\hline & $\begin{array}{l}\text { hsa- } \\
\text { mir- } \\
566\end{array}$ & $\begin{array}{l}\text { ppy- } \\
\text { mir- } \\
566\end{array}$ & $\begin{array}{l}\text { ptr- } \\
\text { mir- } \\
566\end{array}$ & $\begin{array}{l}\text { hsa- } \\
\text { mir- } \\
1273 a\end{array}$ & $\begin{array}{l}\text { hsa- } \\
\text { mir- } \\
1273 d\end{array}$ & $\begin{array}{l}\text { hsa- } \\
\text { mir- } \\
1273 \text { e }\end{array}$ & $\begin{array}{l}\text { ppy- } \\
\text { mir- } \\
1273 a\end{array}$ & $\begin{array}{l}\text { ptr- } \\
\text { mir- } \\
1273\end{array}$ & $\begin{array}{l}\text { hsa- } \\
\text { mir- } \\
1268 a\end{array}$ & $\begin{array}{l}\text { ppy- } \\
\text { mir- } \\
1268\end{array}$ & $\begin{array}{l}\text { hsa- } \\
\text { mir- } \\
3929\end{array}$ & $\begin{array}{l}\text { hsa- } \\
\text { mir- } \\
5096\end{array}$ \\
\hline \multicolumn{13}{|l|}{ GHI } \\
\hline Macaca mulatta & 0 & 0 & 0 & 0 & 0 & 0 & 0 & 0 & 0 & 0 & 0 & 0 \\
\hline Pan troglodytes & 0 & 0 & 0 & 0 & 0 & 0 & 0 & 0 & 0 & 0 & 0 & 0 \\
\hline Pongo abelii & 0 & 0 & 0 & 0 & 0 & 0 & 0 & 0 & 0 & 0 & 0 & 0 \\
\hline Homo sapiens & 0 & 0 & 0 & 0 & 0 & 0 & 0 & 0 & 0 & 0 & 0 & 0 \\
\hline $\begin{array}{l}\text { Gorilla gorilla } \\
\text { GHRH }\end{array}$ & 0 & 0 & 0 & 0 & 0 & 0 & 1 & 0 & 0 & 0 & 0 & 0 \\
\hline Macaca mulatta & 1 & 1 & 0 & 0 & 0 & 0 & 0 & 0 & 1 & 2 & 0 & 1 \\
\hline Pan troglodytes & 0 & 0 & 1 & 0 & 0 & 0 & 0 & 0 & 0 & 0 & 1 & 3 \\
\hline Pongo abelii & 1 & 1 & 0 & 1 & 0 & 1 & 1 & 1 & 0 & 1 & 0 & 4 \\
\hline Homo sapiens & 0 & 0 & 0 & 0 & 0 & 0 & 0 & 0 & 0 & 0 & 0 & 3 \\
\hline $\begin{array}{l}\text { Gorilla gorilla } \\
\text { SST }\end{array}$ & 0 & 0 & 0 & 0 & 0 & 0 & 0 & 0 & 0 & 0 & 0 & 2 \\
\hline Macaca mulatta & 0 & 0 & 0 & 0 & 0 & 0 & 0 & 0 & 0 & 0 & 0 & 0 \\
\hline Pan troglodytes & 0 & 1 & 0 & 0 & 1 & 2 & 0 & 0 & 0 & 1 & 0 & 0 \\
\hline Pongo abelii & 0 & 0 & 0 & 0 & 0 & 0 & 0 & 0 & 0 & 0 & 0 & 0 \\
\hline Homo sapiens & 0 & 0 & 0 & 0 & 0 & 0 & 0 & 0 & 0 & 0 & 0 & 0 \\
\hline $\begin{array}{l}\text { Gorilla gorilla } \\
\text { IGF1 }\end{array}$ & 2 & 0 & 0 & 0 & 1 & 0 & 0 & 0 & 0 & 0 & 0 & 0 \\
\hline Macaca mulatta & 0 & 1 & 0 & 0 & 0 & 0 & 0 & 0 & 0 & 0 & 1 & 2 \\
\hline Pan troglodytes & 2 & 3 & 1 & 0 & 0 & 2 & 0 & 1 & 1 & 1 & 1 & 3 \\
\hline Pongo abelii & 2 & 2 & 1 & 0 & 0 & 3 & 0 & 0 & 0 & 2 & 1 & 1 \\
\hline Homo sapiens & 2 & 3 & 1 & 0 & 0 & 3 & 0 & 1 & 2 & 2 & 1 & 3 \\
\hline Gorilla gorilla & 1 & 1 & 0 & 0 & 0 & 1 & 0 & 0 & 0 & 0 & 1 & 4 \\
\hline
\end{tabular}

We observed only one miRNA copy in the intron of the $G H 1$ gene in gorillas (ppy-mir-1273a).

Single copies of the hsa-mir-566 miRNA were found in the introns of $G H R H$ and SST genes in almost all primates. Greatest number of miRNAs $(57$ copies) were distributed in the introns of the IGF1 gene, namely Macaca mulatta had 4 copies, Gorilla gorilla-8, Pongo abeliib-13 copies, Pan troglodytes15 , Homo sapiens- 18 . Thus it was $72 \%$ of the total number of found miRNAs located within introns and cis-regulatory regions of this gene (30 thousand base pairs upstream and downstream of the gene).

$I G F 1$ is the most important endocrine mediator of the somatotropic hormone activity. IGF1 also provides the feedback with hypothalamus and pituitary by somatotropic axis, i.e., the secretion of somatotropinreleasing hormone and growth hormone depends on IGF1 level in blood. The secretion of somatotropinreleasing hormone and growth hormone increases under low IGF1 level in blood and on the contrary-reduces under its high level.

Currently there is no explanation for the high conservatism of the hsa-mir-566 or hsa-mir-619 hairpin sequences which are widely spread in primates genomes. However, it was shown that the hairpins of all miRNAs are much more highly conserved than DNA sequences in their surroundings. This finding supports the idea of evolutionarily preservation of the hairpin, which binds with related motifs (Hill and Sorscher, 2013).
Further in our work we investigated the prevalence of miRNAs hairpins in non-coding region and the surroundings of the genes.

Analysis of hsa-mir-5096 and hsa-mir-1268Related Hairpins in Somatotropic Axis Genes Surroundings in Mammals

Using GLAM2 analysis in the entire set of the noncoding DNA sequences around GH1, GHRH, SST and IGF1 genes in 12 mammals we found 714 motifs which were more than $85 \%$ homologous to miRNA with a number of different motifs 78 . All motifs, homologous to miRNAs hairpins, were detected only in primates. The greatest number of motifs was detected for the hsa-mir5096 and hsa-mir-1268 genes hairpins (101 and 87 copies respectively). The number of other miRNAs copies varied from 8 to 13 .

In addition to the high copy number hsa-mir-5096 and hsa-mir-1268 motifs, we also observed a high degree of homology, higher than 0.9 (Table 5).

Figure 1 shows the occurrence frequency of a motif homologous to hsa-mir-5096 in the somatotropic axis genes surroundings in primates. The greatest number of the motif copies was observed in the GHRH gene surroundings in every examined primate: 21 copies were detected in chimpanzees, orangutans and humans. The smallest number of copies (3) was observed in the SST gene surroundings in Macaca mulatta. The number of the motif copies in the IGF1 gene surroundings was almost the same (about 7) in all studied primates. 
Among all studied genes, the largest number of the hsa-mir-5096 motif copies, in particular-13, was found before $G H R H$ gene. The distribution of the motif copies number between different areas of the $I G F 1$ gene was equal in all studied primates, what is associated with a high degree of homology of the sequences in the IGFI gene surroundings in these animals. Five of the seven copies are presented in the introns of the $I G F 1$ gene. This motive was not observed in the region after $I G F 1$ gene.
The copy number of the hsa-mir-5096 motif and their distribution around the GH1 gene is almost the same in all primates. The motif copies were not found after the GH1 gene only in gorillas. More precise analysis shows that such redistribution is associated with a significant expansion of the transcribed region of the $\mathrm{GH} 1$ gene in the forward direction in gorillas in comparison with other primates.

The prevalence of the second most frequent motif homologous to hsa-mir-1268 in the somatotropic axis genes surroundings in primates is shown in Fig. 2.

Table 5. Search results fragment of the hsa-mir-5096 gene sequence in different sequence variants

\begin{tabular}{lll}
\hline Motif subsequence & $\begin{array}{l}\text { The similarity } \\
\text { degree with the gene }\end{array}$ & $\begin{array}{l}\text { The similarity degree } \\
\text { with mature transcript }\end{array}$ \\
\hline agtagagAtggggtttcaccaCgttggCcagg ctggtctcaaactcctgacctcaAgtgatccatccGcc & 0.93 & 0.90 \\
agtagagACgggAtttcaccatgttggCcaggctggtctAaaactcctgacctcaAgtgatccatccGcc & 0.90 & 0.90 \\
agtagagAtgggAttcaccaGgttggCcaggctggtctcaaactcctgGcctcaggtgatccGCccacc & 0.90 & 0.86 \\
agtagagAtggggtttcTccatgttggtcaggctggtctcaaactcctgacctcaggtgatcTGCcTGcc & 0.90 & 0.95 \\
agtagagAtgggAttcaccaGgttggCcaggctggtctcaaactcctgGcctcaggtgatccGCccacc & 0.90 & 0.86 \\
agtagagAtggggtttcTccatgttggtcaggctggtctcaaactcctgacctcaggtgatcTGCcTGcc & 0.90 & 0.95 \\
agtaga.gACAggttcaccatgttggCcaggctggtctcGaactcctgacctcaggtgatccaCccacc & 0.90 & 0.95 \\
\hline
\end{tabular}

a. Discriminated nucleotides are highlighted in upper case.

b. The mature transcript sequence is highlighted in red.

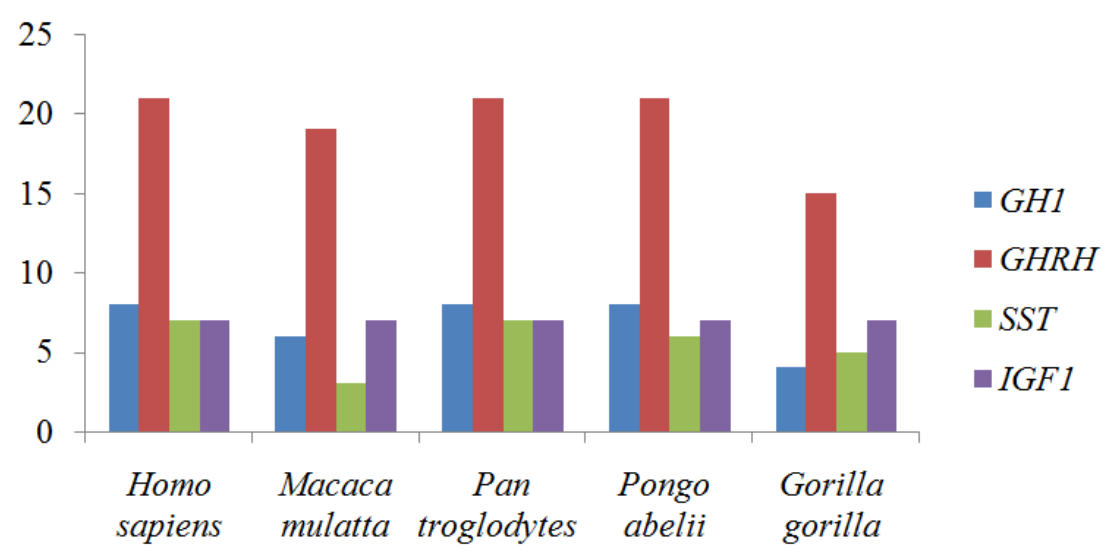

Fig. 1. The number of the hsa-mir-5096 copies in the somatotropic axis genes surroundings in primates

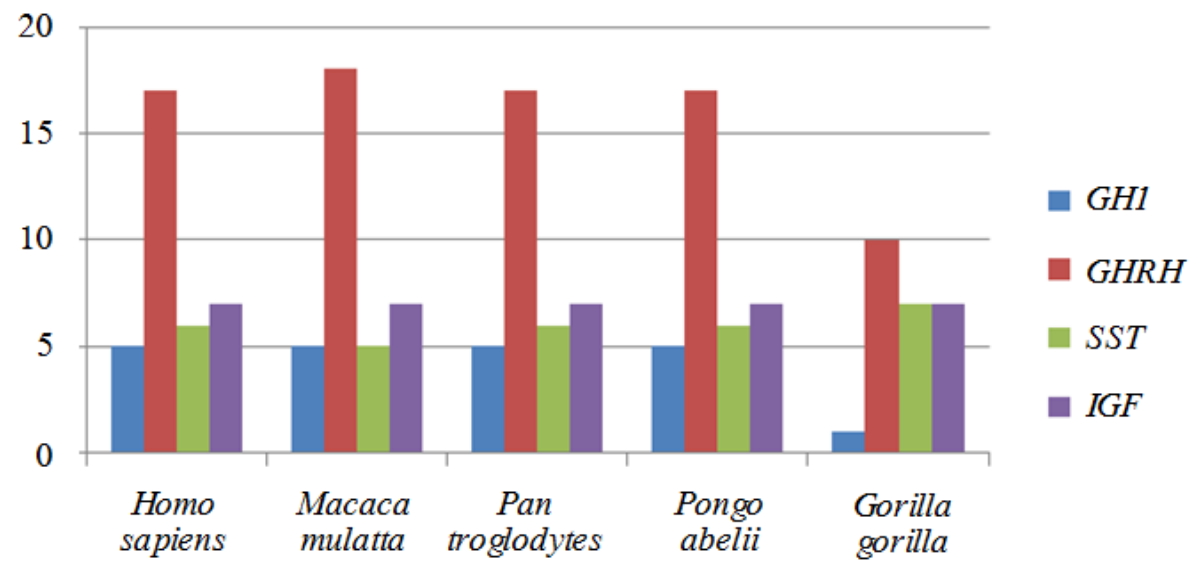

Fig. 2. Copy number of the hsa-mir-1268 ID motif in the somatotropic axis genes surroundings in primates 
The greatest number of the motif copies was detected in the GHRH gene surroundings and the same was observed for every studied primate. In gorilla GH1 gene surroundings the motif was presented in a single copy. The motif copy number was higher in other primates. The greatest copy number (18) of this motif was revealed in the GHRH gene surroundings in Macaca mulatta. The hsa-mir-1268 motive was not found in the introns of the GH1 and SST genes in all primates except gorillas. Among all genes the greatest copy number (12) occurs before the GHRH gene. The distribution of the motif copy number between different regions of the IGFI gene was equal in all studied primates, what is associated with high degree of homology of the $I G F 1$ gene sequences in these animals. And commonly these motif copies were located in the introns of this gene.

\section{Discussion}

Discoveries of the past decade showed that RNA works not only as a functional messenger between DNA and protein, but also participates in regulation and organization of genome, gene expression and its role rises with increasing complexity of the organism (Hill et al., 2005). The important role of RNA was shown in epigenetic processes which control the differentiation and development. These findings indicate that RNA seems to play a central role in human evolution and ontogenesis (Olovnikov, 2007; 2009).

MiRNAs being functional participants in the gene networks regulation inhibit the expression of the miRNAs targets. There is a growing interest in the involvement of miRNAs in important cellular functions and biological processes and identification of the relationship between miRNAs and their targets (Gregory et al., 2008; Jones et al., 2014).

Earlier it was shown that miRNAs participate in the formation of species morphological diversity (Heimberg et al., 2008), as well as the miRNAs accumulation in tissues correlates with the morphological changes rates (Wheeler et al., 2009). The complexity of organisms rises with the increasing proportion of transcribed but not translated regions of the genome, with increasing length and number of introns in protein-coding genes, with the increasing number of regulatory elements required for the each gene expression regulation, with the increasing number of the transcription factors binding sites in the genome (Chinwalla et al., 2002; Levine and Tjian, 2003). The number of introns also increases with phylogenetic complexity of organisms (Hill et al., 2005). MiRNAs are important phylogenetic markers because of their strikingly low rate of evolution (Wheeler et al., 2009 Ivashchenko et al., 2014). Most probably that is why mir-599, mir-1273, mir-1268, hsa-mir-5096, we found only in primates. It can be phylogenetic markers.
On the other hand the $\mathrm{GH}$ protein, encoded by the GH1 gene, plays an important role in human development, growth and metabolism. It is known that growth hormone is a powerful regulator of postnatal growth development and its level affects the final size of the body. Our results showed a significant difference in the copy number of the investigated miRNAs in the intergenic space of $G H 1$ gene and its receptor $(G H R H)$ for all primates. We assume that the discovered miRNAs play an important role in the formation of morphological and physiological traits such as weight and height in mammals.

\section{Conclusion}

Our results showed that miRNAs-mir-566, mir1273, mir-1268, hsa-mir-5096 and hsa-mir-3929 play an important role in the formation of morphological and physiological characteristics, such as weight and height in mammals.

\section{Acknowledgement}

This research was supported by the project of the Ministry of Education and Science of Russia №6.703.2014/K «The search of new targets for predictive diagnostics of the reproductive system diseases». Analytical work was carried out on the equipment of Center for collective use of Southern Federal University «High Technology», grant RFMEFI59414X0002.

\section{Funding Information}

This article was funded by the Ministry of Education and Science of Russia, project №6.703.2014/K «The search of new targets for predictive diagnostics of the reproductive system diseases». The funders had no role in study design, data collection and analysis, decision to publish, or preparation of the manuscript.

\section{Author's Contributions}

Tatiana Shkurat: Designed the research plan and organized the study.

Dmitry Romanov: Computer analysis and contributed to the writing of the manuscript.

Evgeny Pshenichnyy: Computer analysis and contributed to the writing of the manuscript.

Natalya Ponomareva: Participated in all experiments, coordinated the data-analysis and contributed to the writing of the manuscript.

Anzela Alexsandrova: Participated in all experiments and contributed to the writing of the manuscript.

Georgy Bakhtadze: Collect data on the physiological characteristics of animals and contributed to the writing of the manuscript.

Svetlana Lomteva: Participated in all experiments, coordinated the data-analysis and contributed to the writing of the manuscript. 


\section{Ethics}

This article is original and contains unpublished material. The corresponding author confirms that all of other authors have read and approved the manuscript and no ethical issues involved.

\section{References}

Bartel, D.P., 2004. MicroRNAs: Genomics, biogenesis, mechanism and function. Cell, 116: 281-297. PMID: 14744438

Chandra, V., R. Girijadevi, A.S. Nair, S.S. Pillai and R.M. Pillai, 2010. MTar: A computational microRNA target prediction architecture for human transcriptome. BMC Bioinformatics, 11: S2-S2. DOI: $10.1186 / 1471-2105-11-S 1-S 2$

Chinwalla, A.T., R.H. Waterston, E. Birney, J. Rogers and J.F. Abril et al., 2002. Initial sequencing and comparative analysis of the mouse genome. Nature, 420: 520-562. PMID: 12466850

Ecker, J.R., W.A. Bickmore, I. Barroso, J.K. Pritchard and Y. Gilad et al., 2012. Genomics: ENCODE explained. Nature, 489: 52-55. PMID: 22955614

Gregory, P.A., A.G. Bert, E.L. Paterson, S.C. Barry and A. Tsykin et al., 2008. The miR-200 family and miR-205 regulate epithelial to mesenchymal transition by targeting ZEB1 and SIP1. Natural Cell Biol., 10: 593-601. PMID: 18376396

Heimberg, A.M., L.F. Sempere, V.N. Moy, P.C. Donog-hue and K.J. Peterson, 2008. MicroRNAs and the advent of vertebrate morphological complexity. Proc. National Acad. Sci. United States Am., 105: 2946-2950.

DOI: $10.1073 /$ pnas.0712259105

Hill, A.E. and E.J. Sorscher, 2013. Massive microRNA sequence conservation and prevalence in human and chimpanzee introns. Frontiers Biosci., 5: 814-822. PMID: 23747898

Hill, A.E., J.S. Hong, H. Wen, L. Teng and D.T. McPherson et al., 2005. Micro-RNA-like effects of complete intronic sequences. Frontiers Biosci, 11: 1998-2006. PMID: 16368574
Ivashchenko, A., O. Berillo, A. Pyrkova, R. Niyazova and S. Atambayeva. 2014. The properties of binding sites of miR-619-5p, miR-5095, miR-5096 and miR$5585-3 p$ in the mRNAs of human genes. BioMed Res. Int., 2014: 1674-1684. DOI: $10.1155 / 2014 / 720715$

Jones, K., J.P. Nourse, C. Keane, A. Bhatnagar and M.K. Gandhi, 2014. Plasma microRNA are disease response biomarkers in classical Hodgkin lymphoma. Clin. Cancer Res., 20: 253-264. DOI: 10.1158/1078-0432.CCR-13-1024

Levine, M. and R. Tjian, 2003. Transcription regulation and animal diversity. Nature, 424: 147-151. PMID: 12853946

Mallo, F., C.V. Alvarez, L. Benitez, B. Burguera and R. Coya et al., 1993. Regulation of His-dTrp-Ala-TrpdPhe-Lys-NH2 (GHRP-6)-induced GH secretion in the rat. Neuroendocrinology, 57: 247-256. PMID: 8510800

Oldham, S., R. Böhni, H. Stocker, W. Brogiolo and E. Hafen, 2000. Genetic control of size in Drosophila. Philos. Trans. Royal Society Lond. Series B: Biological Sci., 355: 945-952. DOI: $10.1098 /$ rstb.2000.0630

Olovnikov, A.M., 2007. Role of paragenome in development. Russian J. Develop. Biol., 38: 104123. DOI: $10.1134 / \mathrm{S} 1062360407020075$

Olovnikov, A.M., 2009. Biological evolution based on nonrandom variability regulated by the organism. Biochemistry, 74: 1404-1408. PMID: 19961425

Qian, J., V. Siragam, J. Lin, J. Ma and Z. Deng, 2011. The role of microRNAs in the formation of cancer stem cells: Future directions for miRNAs. Hypothesis.

Shkurat, T.P., N.S. Ponomareva, A.I. Butenko, P.A. Ryzkov and U.V. Denisenko, 2013. Analysis of the DNA nucleotide sequences using dot matrix of homology.

Wheeler, B.M., A.M. Heimberg, V.N. Moy, E.A. Sperling and T.W. Holstein et al., 2009. The deep evolution of metazoan microRNAs. Evolut. Develop., 11: 50-68. PMID: 19196333 